\title{
Polikistik over sendromunda klomifen sitrat ile ovulasyon indüksiyonunun serum leptin düzeylerine etkisi
}

The effect of ovulation induction with clomiphene citrate on serum leptin levels in polycystic ovary syndrome

Ayşen Güçlü ${ }^{1} \quad$ Ümit Nayki ${ }^{2}$ Cenk Nayki ${ }^{2} \quad$ Mehmet Kulhan $^{3} \quad$ Salih Sadık $^{3}$

${ }^{1}$ İzmir Özel Egepol Hastanesi, Kadın Hastalıkları ve Doğum Kliniği, İzmir, Türkiye

${ }^{2}$ Erzincan Üniversitesi Tıp Fakültesi, Kadın Hastalıkları ve Doğum Anabilim Dalı, Erzincan, Türkiye

${ }^{3}$ Tepecik Eğitim ve Araştırma Hastanesi, Kadın Hastalıkları ve Doğum Kliniği, İzmir, Türkiye

\section{Öz}

Amaç: Bu çalışmada, polikistik over sendromu (PKOS) bulunan infertil kadınlarda, klomifen sitrat (KS) ile ovulasyon indüksiyonun serum leptin düzeylerine etkisini araştırmayı amaçladık.

Gereç ve Yöntem: PKOS'li infertil 40 kadında KS tedavisi öncesi ve sonrası serum leptin düzeyleri değerlendirildi. Hastalar vücut kitle indeksine (VKI) göre Grup $1\left(\mathrm{VKI}<25 \mathrm{~kg} / \mathrm{m}^{2}\right)$ ve Grup $2\left(\mathrm{VKI} \geq 25 \mathrm{~kg} / \mathrm{m}^{2}\right)$ olarak iki gruba ayrıldı.

Bulgular: Tedavi öncesi bazal leptin seviyelerinin ortalama değeri $31.7 \pm 23.0 \mathrm{ng} / \mathrm{mL}$ iken, tedavi sonrası leptin düzeyinin ortalama değeri $35.6 \pm 23.0 \mathrm{ng} / \mathrm{mL}$ idi. Tedavi öncesi bazal leptin seviyeleri ile tedavi sonrası leptin seviyeleri arasında istatistiki belirgin fark saptanmadı $(p>0.05)$. Grup 2'deki tedavi öncesi ve sonrası serum leptin düzeyleri Grup 1'deki hastalara göre daha yüksekti. Bu fark istatistiksel olarak anlamlı bulundu $(p<0.005)$.

Sonuç: PKOS'li hastalarda KS'nin 3 aylık tedavi süresinde serum leptin düzeyleri üzerine etkisi saptanmamıştır. Ancak serum leptin düzeyi ile VKI arasındaki kuvvetli ilişkiye rağmen, PKOS'de CC tedavisine ovaryan yanıın değerlendirilmesinde leptinin yeri olmadığı kanaatindeyiz.

Anahtar Sözcükler: Polikistik over sendromu, vücut kitle indeksi, klomifen sitrat, leptin.

\section{Abstract}

Aim: We aimed to assess the effect of ovulation induction with clomiphene citrate on serum leptin levels in infertile women with polycystic ovary syndrome (PCOS).

Materials and Methods: Serum leptin levels were evaluated before and after clomiphene citrate (CC) therapy in 40 infertile women with PCOS. According to body mass index (BMI), the patients were divided into two groups as Group $1\left(B M l<25 \mathrm{~kg} / \mathrm{m}^{2}\right)$ and Group $2\left(B M l \geq 25 \mathrm{~kg} / \mathrm{m}^{2}\right)$

Results: The mean of basal leptin concentrations before CC therapy was $31.7 \pm 23.0 \mathrm{ng} / \mathrm{mL}$ while it was $35.6 \pm 23.0$ $\mathrm{ng} / \mathrm{mL}$ after CC therapy. There was not any significant differrence between basal leptin levels before and after CC therapy ( $p>0.05$ ). However, before and after CC therapy, serum levels were higher in Group 2 than in Group 1; the difference was statistically significant $(p<0.05)$.

Conclusion: We did not observe any effect of $C C$ on serum leptin concentrations in patients with $P C O S$ after a three month CC therapy. However there is a strong relationship between serum leptin and BMI, we are of the opinion that leptin does not have a role in the evaluation of response to CC in PCOS.

Keywords: Polycystic ovary syndrome, body mass index, clomiphene citrate, leptin.

\footnotetext{
Yazışma Adresi: Ümit Nayki

Erzincan Üniversitesi Tıp Fakültesi, Kadın Hastalıkları ve

Doğum Anabilim Dalı, Erzincan, Türkiye

Makalenin Geliş Tarihi: 28.12.2014 Kabul Tarihi: 02.03.2015
} 


\section{Giriş}

Polikistik over sendromu (PKOS), üreme çağındaki kadınların \%5 ile \%10'nu etkileyen bir endokrinopatidir (1). PKOS; anovulasyon, menstrüel bozukluk (oligoamenore) ve hiperandrojenizm ile karakterizedir (2). Hiperandrojenemi, hiperinsulinemi ve/veya insülin rezistansı PKOS patogenezinde önemli rol oynamaktadır ve her zaman olmamakla beraber, sıklıkla obezite de PKOS'ye eşlik etmektedir (3).

Obezite gen ürünü olan leptinin beslenme, vücut enerji dengesi ve reprodüktif aksta önemli rolü vardır (4). Kadınlarda üreme fonksiyonları beslenme durumu ve enerji kullanımına göre geri dönüşümlü olabilen değişikliklere uğrayabilir $(5,6)$. Leptin over fonksiyonlarının regülasyonunda doğrudan fizyolojik rol üstlendiği gibi enerji dengesinin regülasyonundaki rolü sebebiyle vücut kitle indeksi ile de pozitif korelasyon gösterir (7). Leptin menstrüel siklus boyunca dalgalanmalar gösterir ve luteal fazda progesterona paralel şekilde pik yapar $(8,9)$. Bu durum, hipotalo-hipofizer aks ile leptin arasındaki muhtemel bir pozitif geri dönüşümü göstermektedir. Diğer yandan hipotalamo-hipofizer aksta leptin reseptörleri ve mRNA; granulosa hücreleri, oositeler ve erken evre embriyolarda da leptin reseptörleri ve protein ürünlerinin varlığı gösterilmiştir (10-12). Ancak leptin üreme sisteminde yaygın olarak bulunmasına rağmen, üreme hormonları ile arasındaki ilişki henüz net olarak anlaşılamamıştır.

Obezite ve insülin rezistansının, leptin ve leptin reseptörleri ile ilişkisi bilinmektedir $(13,14)$. Son zamanlarda leptinin PKOS patogenezinde rolü olduğuna dair yayınlar artmaktadır (15,16). Yüksek leptin seviyelerinin $\mathrm{GnRH}$ nöronları, pitüiter gonadotroplar veya overler seviyesinde PKOS patofizyolojisi ile ilişkili olabileceği düşünülmektedir $(16,17)$. Ancak, bazı çalışmalarda infertil PKOS olgularında leptin konsantrasyonu, fertil normal kontrollerine göre yüksek bulunurken, bazı çalışmalarda fark olmadığı bildirilmiştir $(1,18,19)$.

PKOS, üreme çağındaki kadınlarda disovulatuvar infertilitenin en sık sebebi olup, bu hastalarda ovulasyon klomifen sitrat (KS) ve gonadotropinlerle sağlanabilmektedir. Literatürde PKOS, obezite, serum leptin düzeyleri arasındaki ilişkiyi inceleyen birçok çalışma mevcuttur. Ancak, PKOS'lu hastalarda infertilite tedavisinin serum leptin seviyelerine etkisiyle ilgili çalışma bulunmamaktadır.

Biz bu çalışmada, PKOS tanısı almış infertil kadınlarda, $\mathrm{KS}+$ human koryonik gonadotropin (hCG) tedavisi öncesi ve sonrası serum leptin konsantrasyonları üzerine etkisini ve bu bağlamda bu hastalarda tedaviye yanıtın değerlendirilmesinde leptinin rolünü araştırmayı amaçladık.

\section{Gereç ve Yöntem}

Başlangıçta, çalışmaya T.C Sağlık Bakanlığı Tepecik Eğitim ve Araştırma Hastanesi, Kadın Hastalıkları ve Doğum Bölümü infertilite kliniğine başvuran, spermiyogram ve ürolojik değerlendirme ile erkek infertilitesi ve histerosalpingografi ile tubal faktörler ekarte edilen ve klinik, ultrasonografik ve biyokimyasal değerlendirmeler sonucu ESHRE/ASRM tarafından oluşturulan Rotterdam kriterlerine [menstrüel düzensizlik, oligo-amenore, klinik (hirsutismus) veya biyokimyasal hiperandrojenite ve ultrasonografide polikistik over varlığı] göre PKOS tanısı alan infertil 55 kadın alındı (2). Hastalar oligo veya amenoreikti. Ultrasonografide artmış stromanın yanında multipl küçük subkortikal folliküller içeren büyümüş over varlığı kriter olarak alındı. Hastalarda hirsutismus modifiye Ferriman Gallwey (mFG) skorlaması ile biyokimyasal hiperandrojenite ise kanda serbest testosteron (sT) ile değerlendirildi. mFG skoru 8 ve üzeri hastalar, hirsutimus olarak değerlendirildi $(20,21)$. Hastalar en az 1 yıldır infertil ve çocuk istemi mevcut olan hastalardı ve daha önce infertilite nedeniyle herhangi bir tedavi almamışlardı. Hastalara KS + hCG ile ovulasyon indüksiyonu 3 ay süre ile uygulandı. Tedavi sonrasında gebelik elde edilemeyen 40 hasta çalışmaya dahil edildi.

Hastalar, çalışma hakkında bilgilendirilerek yazılı onamları alındı. Ayrıca çalışmamız için lokal Etik Kurul'dan onay alındı.

Hastaların, kilo ve boyları ölçülerek vücut kitle indeksleri (VKI) $\mathrm{kg} / \mathrm{m}^{2}$ olarak hesaplandı. Çalışmaya dahil edilen hastalar VKI $<25 \mathrm{~kg} / \mathrm{m}^{2}$ (Grup 1) ve VKI $\geq 25 \mathrm{~kg} / \mathrm{m}^{2}$ (Grup 2) olarak 2 alt gruba ayrıldı.

Tüm hastalardan venöz kan örnekleri menstrüel siklusun 3. gününde sabah saat 08:00 ile 10:00 arasında 8 saatlik açlığı takiben alındı. Adet düzensizliği ve amenore şikayeti olan olgularda gestagen testi (medroksiprogesteton asetat, $10 \mathrm{mg} /$ gün, 6 gün kullanıldı) ile kanama oluşturulduktan sonra yine menstrüel siklusun 3.gününde aynı koşular sağlanarak venöz kan örnekleri elde edildi. Alınan kan örneklerinde serumda leptin, luteinizan hormon (LH), follikül stimulan hormon (FSH), prolaktin (PRL), östrodiol (E2), sT, DHEAS, tiroid stimulan hormon (TSH) konsantrasyonları ölçüldü. Hastalara siklusun 5-9.günleri arasında 50 $\mathrm{mg} /$ gün KS tedavisi verildi. Dominant follikül (>18 mm) oluşana kadar vajinal ultrasonografi ile takip edildi. Ultrasonografik değerlendirmede dominant follikül tespit edilen hastalara intramüsküler 10.000 hCG uygulandı. Ovulasyon takibi midluteal fazda progesteron seviyeleri bakılarak değerlendirildi. Progesteron için eşik değer 12 ng/dL olarak kabul edildi (22). Ovaryan cevabın olmadığı olgularda doz her siklus $50 \mathrm{mg}$ artırılarak toplam doz 150 mg/gün'e kadar artırıldı. Tedavi sırasında gebelik oluşan hastalar çalışmadan çıkartıldı. Üç ay süre ile KS + hCG 
tedavisi uygulanan ve gebelik oluşmayan 40 hastada tedavi sonrasında serum bazal leptin konsantrasyonları tekrar ölçüldü. Leptinin normal serum düzeyi 12-23 $\mathrm{ng} / \mathrm{dL}$ olarak kabul edildi (14).

Serum LH, FSH, PRL, $E_{2}, T S H, F T$ ve DHEA-S seviyeleri, Immulite 2000 cihazında chemiluminescent enzyme immunoassay tekniği ile ölçüldü. Serum leptin seviyesi ise ISOCOMP-1 MGM marka gamacounter cihazında IRMA metodu ile DSL marka kit (Human Leptin RIA kit, Diagnostic Systems Laboratories, Webster, Texas, USA) kullanılarak ölçüldü.

İstatistiksel analizler için SPSS (10.0) for Windows paket programı kullanıldı. Elde edilen verilerin karşılaştırılmasında çapraz tablolarda Chi-square testi, tedavi öncesi ve sonrası serum leptin düzeyleri arasındaki farkı belirlemek için $T$ test ve Wilcoxon testi kullanıldı. $p<0.05$ değerleri istatistiksel olarak anlamlı kabul edildi.

\section{Bulgular}

Hastaların yaş ortalaması 28 (21-34), ortalama infertilite süresi 5.9 yıl olarak saptandı. Hastaların \%78'inde LH/FSH oranı 2'den büyük , \%15'inde PRL (5-25 ng/mL) ve \%68'inde sT (0.4-2.4 ng/dL) yüksekti. TSH (0.4-4.0 $\mathrm{mIU} / \mathrm{L})$ ve DHEA-S $(35-430 \mu \mathrm{g} / \mathrm{dL})$ tüm hastalarda normal sınırlar içerisindeydi. Grup $1\left(\mathrm{VKI}<25 \mathrm{~kg} / \mathrm{m}^{2}\right) 15$ hasta ve Grup $2 \quad\left(\mathrm{VKI}>25 \quad \mathrm{~kg} / \mathrm{m}^{2}\right) \quad 25$ hastadan oluşmaktaydı. FG skoru 8 den büyük hasta sayısı Grup 1'de 13 iken Grup 2'de 14 olarak saptandı. Gruplar yaş, infertilite süreleri, LH/FSH oranı, PRL, ST değerleri açısından karşılaştırıldığında istatiksel olarak anlamlı bir fark saptanmadı $(p>0.05)$ (Tablo-1). Her 2 grup mFG skoru açısından ki-kare testi ile karşılaştırıldığında fark istatiksel olarak anlamlı idi $(p<0.05)$.

Tablo-1. VKi ile İnfertilite Süresi, FSH/LH, PRL, s-T'nun Karşılaştırılması *

\begin{tabular}{|c|c|c|c|c|}
\hline & & \multicolumn{2}{|c|}{ VKi $\left(\mathbf{k g} / \mathbf{m}^{2}\right)$} & \multirow{2}{*}{$\begin{array}{c}p \\
\text { değeri" }\end{array}$} \\
\hline & & $\begin{array}{c}\text { NORMAL } \\
\left(\mathrm{VKI}<25 \mathrm{~kg} / \mathrm{m}^{2}\right) \\
n\end{array}$ & $\begin{array}{c}\text { OBEZ } \\
\left(\mathrm{VKi} \geq 25 \mathrm{~kg} / \mathrm{m}^{2}\right) \\
n\end{array}$ & \\
\hline LH/FSH & $<2$ & 4 & 5 & NS \\
\hline \multirow{3}{*}{$\underset{(\mathbf{n g} / \mathbf{m L})}{\mathrm{PRL}}$} & $>2$ & 11 & 20 & NS \\
\hline & $<25$ & 13 & 21 & NS \\
\hline & $>25$ & 2 & 4 & NS \\
\hline \multirow[t]{2}{*}{$\begin{array}{c}\mathrm{s}-\mathrm{T} \\
(\mathrm{ng} / \mathrm{mL})\end{array}$} & $<2.5$ & 3 & 10 & NS \\
\hline & $>2.5$ & 12 & 15 & NS \\
\hline
\end{tabular}

*: FSH: Follikül stimule edici hormon, PRL: Prolaktin, LH: Lüteinize edici hormon, $\mathrm{s}-\mathrm{T}$ : Serbest testosteron, NS: Anlamsız $(\mathrm{p}>0.05) .{ }^{* *} \mathrm{Ki}-\mathrm{kare}$ testine göre

Bazal leptin seviyelerinin ortalama değeri $31.7 \pm 23.0$ $\mathrm{ng} / \mathrm{mL}$ iken, tedavi sonrası leptin düzeyinin ortalama değeri $35.6 \pm 23.0 \mathrm{ng} / \mathrm{mL}$ idi (Tablo-2). Çalışma grubunda basal serum leptin seviyesi tedavi öncesi ve sonrası normal değerlerin üzerinde olup, tedavi öncesi bazal leptin seviyeleri ile tedavi sonrası leptin seviyeleri arasında istatistiki belirgin fark saptanmadı $(p>0.05)$. Her iki grup, bazal ve tedavi sonrası serum leptin seviyeleri açısından karşılaştırıldığında; Grup 2'deki tedavi öncesi ve sonrası serum leptin düzeyleri Grup 1'deki hastalara göre daha yüksekti. Bu fark Mann Whitney $U$ testine göre istatistiksel olarak anlamlı bulundu $(p<0.05)$.

LH/FSH oranı 2'den büyük olan hastalarda bazal leptin değerleri LH/FSH 2'den küçük olan hastalardan yüksekti. $\mathrm{Bu}$ fark $t$ teste göre istatistiksel olarak anlamlı idi $(p<0.05)$ (Tablo-3).

Tablo-2. Tedavi Öncesi ve Sonrası Ortalama Serum Leptin Seviyeleri.

\begin{tabular}{lcc}
\hline & $\begin{array}{c}\text { Tedavi öncesi } \\
\text { serum leptin } \\
\text { düzeyi }(\mathbf{n g} / \mathbf{m L} \text { ) }\end{array}$ & $\begin{array}{c}\text { Tedavi sonrası } \\
\text { serum leptin } \\
\text { düzeyi }(\mathbf{n g} / \mathbf{m L})\end{array}$ \\
\hline Ortalama (Ort.) & 31.71 & 35.64 \\
Standart sapma (SD) & 22.97 & 23.09 \\
Minimum & 5.11 & 3.63 \\
Maksimum & 101.75 & 103.45 \\
\hline
\end{tabular}

Tablo-3. LH/FSH Oranının Bazal Leptin Seviyesi ile Karşılaştırııması.

\begin{tabular}{lcccc}
\hline & LH / FSH & $\mathbf{n}$ & Ort. \pm SD & \\
\hline Bazal leptin & $<2$ & 9 & $18.05 \pm 5.31$ & $\mathrm{t}=-2.093$ \\
seviyesi $(\mathbf{n g} / \mathrm{mL})$ & $>2$ & 31 & $35.54 \pm 24.68$ & $\mathrm{p}<0.05$ \\
\hline
\end{tabular}

\section{Tartışma}

Leptinin obezite ve beslenme bozukluğunda menstrüel düzensizlikten sorumlu bulunması PKOS olgularında da rol oynayabileceğini düşündürmüştür. $\mathrm{PKOS}$ 'de serum leptin seviyeleriyle ilgili birçok çalışma yapılmıştır. Bunlardan bazılarında serum leptin seviyeleri PKOS'li kadınlarda yüksek bulunurken $(13,23,24)$, bazılarında ise serum leptin seviyeleri PKOS'li kadınlarda normal kontrollerinden farklı bulunmamıştır (16). Çalışmamızda da basal serum leptin düzeyleri PKOS'li hastalarda normal değerlerin üstünde saptanmıştır. Diğer yandan leptinin obezite ile arasındaki pozitif korelasyon bilinmektedir. Önceki çalışmalar kilonun infertilitedeki kritik rolünü ortaya koymuşlardır $(25,26)$. Obezite de sıklıkla PKOS'ye eşlik etmekte olup, PKOS da leptin düzeyleri vücut yağ kitlesi ile ilişkili olabilir. Genellikle literatürdeki çalışmalar obezitenin eşlik ettiği PKOS'li olguları içermekte olup, VKi $\geq 25 \mathrm{~kg} / \mathrm{m}^{2}$ olan PKOS'li kadınlarda leptin düzeyleri daha yüksek saptanmıştır $(27,28)$. Diğer yandan, Garrutti ve ark. (29), obez olmayan PKOS'li kadınlarda yaptıkları çalışmalarında serum leptin düzeylerini obez olmayan normal kontrollerine göre düşük olarak bulmuşlardır. Çalışmamızda, obez hastalarda tedavi öncesi ve sonrası serum leptin düzeyleri obez olmayan hastalara göre daha 
yüksek bulunmuş olup, sonuçlarımız literatür ile uyumludur.

Leptin üreme sisteminde yaygın olarak bulunmasına rağmen, üreme hormonları ile arasındaki ilişki henüz net olarak anlaşılamamıştır. Ob/ob farelerde leptin tedavisinin dolaşımdaki gonadotropin seviyelerini artırması leptinin direkt olarak hipotalamus ve/veya pituiter bez üzerinde etkili olduğunu düşündürmektedir (17). Ancak literatürde bazı çalışmalar bu tezi desteklememektedir. Örneğin, Çimen ve ark. (30), yüksek leptin seviyelerinin LH, FSH ve LH/FSH oranındaki değişiklikler ile ilgili olmadığını bildirmişlerdir. Brezechffa ve Rouru'nun $(18,23)$ çalışmaları da bu sonuçları desteklemektedir. Chapman ve ark. (31) ise, PKOS'de serum leptin düzeyleri ile antropometrik ve metabolik parametrelerin ilişkisini inceledikleri çalışmalarında PKOS'li hastalarda VKI, serum leptin, testosteron, DHEAS, androstenedion, progesteron, LH düzeyleri ve insülin cevabını değerlendirmişler; ve PKOS'de serum insulin, gonadotropin ya da seks hormonlarından bağımsız olarak VKİ ile ilişkili olduğunu öne sürmüşlerdir (31). Diğer yandan, PKOS'de leptin ile seks hormon bağlayıcı globulin (SHBG), gonadotropinler ve androjenlerin ilişkisinin incelendiği başka bir çalışmada ise serum leptini ile 24 saatlik ortalama LH seviyesi arasında negatif bir korelasyon bulunmuştur. Yine aynı çalışmada, leptin seviyesi ile östrogen ve androjen seviyeleri arasında bir korelasyon saptanmamıştır (19). Spritzer ve ark. (32) da, PKOS'li hastalarda VKI ve insulinden bağımsız olarak leptin ve LH konsantrasyonları arasında negatif bir korelasyon bildirmişlerdir. Çalışmamızda LH/FSH oranı 2'den yüksek olan PKOS'li hastalarda serum leptin seviyelerini daha yüksek bulduk.

PKOS'de çeşitli amaçlarla kullanılan tedavilerin serum leptin seviyesi üzerine etkileri ile yapılmış çalışmalar az sayıdadır. Şahin ve ark. (33), 20 PKOS'li ve 20 normal kontrol grubunda flutamid tedavisininin leptin seviyesi üzerine etkilerini araştırmışlar ve PKOS'li kadınlarda flutamid tedavisinin serum leptin seviyelerini artırdığını bildirmişlerdir. Yine başka bir çalışmada PKOS'li hastalarda etinil estradiol ve drospirenon içeren düşük dozlu oral kontraseptiflerin 3 aylık periodda leptin seviyelerini değiştirmediği öne sürülmüştür (34). KS ile ovulasyon indüksiyonun leptin düzeylerine etkisi ile ilgili literatüredeki tek çalışma Imani ve ark. (35) aittir. Bu çalışmada 182 normogonadotropik oligomenoreik infertil hastaya 3 ay süre ile $\mathrm{KS}$ tedavisi uygulanmıştır. KS, adetin 3-7.günleri arasında $50 \mathrm{mg} / \mathrm{gün}$ dozunda başlanıp, ovulasyona yanıt olmaması durumunda giderek artırılarak azami 150 mg/gün'e kadar çıkılmıştır. 3 aylık tedavi sonucunda KS'ye yanıt veren hastalarla yanıt vermeyen hastalarda leptin düzeyleri incelenmiş ve serum leptin düzeyleri KS'ye yanıtsız anovulatuvar hastalarda yüksek bulunmuştur. Çalışmanın sonucunda leptinin KS'ye yanıtı öngörmede VKI'ne göre daha iyi bir belirteç olduğu öne sürülmüştür. Biz ise çalışmamızda 3 aylık takip sonucunda KS + hCG uygulanan PKOS'li hastalarda tedavi öncesi ve sonrası serum leptin düzeylerinin değişmediğini gördük.

$\mathrm{Ne}$ var ki, çalışmamızda bazı limitasyonlar söz konusudur. Öncelikle, çalışmamızda KS'nin dozu standart olmayıp, hastalar 3 aylık periodda farklı KS dozlarına yanıt vermiş ancak hasta sayısının azlığı nedeniyle tedavinin leptin düzeylerine üzerine etkisi, verilen KS dozuna göre değerlendirilmemiştir. Daha fazla hasta sayısı ile yapılacak bir çalışmada farklı KS dozlarına göre farklı leptin yanıtları söz konusu olabilir. Ayrıca literatürde yapılmış benzeri çalışmalarda olduğu gibi leptin düzeyleri KS tedavi öncesi ve 3 aylık tedavi sonrasında bakılmıştır. Tedavi sırasında veya bitiminde olmak üzere farklı zamanlarda leptin düzeyleri değerlendirilmemiştir. Bu, leptinin PKOS'de pulsatil salınımının değişip değişmediği konusunda önemli olabilir. Ancak, çalışmamız PKOS, ovulasyon indüksiyonu ve leptin arasındaki ilişkiyi değerlendiren literatürdeki tek çalışma olması ve bundan sonra yapılacak daha geniş kapsamlı çalışmalara öncülük etmesi açısından önemlidir.

\section{Sonuç}

PKOS'li kadınlarda serum leptin düzeyi ile ilgili birbiriyle çelişen çalışmalar mevcuttur. Bu farklı sonuçların nedenleri; VKI ve insülin rezistansının PKOS ile birlikteliği ve bu iki etkenin leptin seviyeleri üzerine direkt etkilerinin yanı sıra leptinin pulsatil salınımının PKOS'de değişip değişmediğinin bilinmemesi olabilir. Diğer yandan, PKOS'de tedavi amacıyla kullanılan değişik ajanların serum leptin seviyelerine etkisi bilinmemektedir. Bu çalışmada, PKOS'li hastalarda KS'ın serum leptin düzeyleri üzerine etkisi saptanmamıştır. Bulgularımız ışığında, PKOS'de KS tedavisine ovaryan yanıtın değerlendirilmesinde leptinin yeri olmadığı kanaatindeyiz. Bu konunun aydınlatılmasında daha kapsamlı çalışmalara ihtiyaç duyulmaktadır.

\section{Kaynaklar}

1. Chakrabarti J. Serum leptin level in women with polycystic ovary syndrome: Correlation with adiposity, insulin, and circulating testosterone. Ann Med Health Sci Res 2013;3(2):191-6.

2. Amsterdam ESHRE/ASRM-Sponsored 3rd PCOS Consensus Workshop Group. Consensus on women's health aspects of polycysticovary syndrome (PCOS). Human Reproduction 2012;27(1):14-24.

3. Dunaif $A$, Wu X, Lee A, Diamanti-Kandarakis $E$. Defects in insulin receptor signaling in vivo in the polycystic ovary syndrome (PCOS). Am J Physiol Endocrinol Metab 2001;281(2):392-9. 
4. Clark AM, Ledger W, Galletly C, et al. Weight loss results in significant improvement in pregnancy and ovulation rates in anovulatuary obese women. Hum Reprod 1995;10(10):2705-12.

5. Lonnqvist F, Arner P, Nordfors L, Schalling M. Overexpression of the obese (ob) gene in adipose tissue of human obese subjects. Nat Med 1995;1(9):950-3.

6. Rogers J, Mitchell GW Jr. The relation of obesity to menstruel disturbances. N Engl J Med 1952;247(2):53-5.

7. Kaseki H, Maruyama S, Ishihara K, Araki T. Serum leptin concentration in young adult women with ovulatuary dysfunction. J Nippon Med Sch 2003;70(3):270-3.

8. Goumenou AG, Matalliotakis IM, Koumantakis GE, Panidis DK. The role of leptin in fertility. European J Obstet \& Gynecol Reprod Biol 2003;106(10):118-24.

9. Hardie L, Trayhurn P, Abramovich D, Fowler P. Circulating leptin in women a longitudinal study in the menstruel cycle and during pregnancy. Clin Endocrinol 1997;47(1):101-6.

10. Finn PD, Cunningham MJ, Pau KY, Spies HG, Clifton DK, Steiner RA. The stimulatory effect of leptin on the neuroendocrine reproductive axis of the monkey. Endocrinology 1998;139(11):4652-62.

11. Clioffi JA, Van Blerkom J, Antczak M, Shafer A, Wittmer S, Snodgrass HR. The expression of leptin and its receptors in preovulatory human follicles. Mol Hum Reprod 1997;3(6):467-72.

12. Brannian JD, Hansen KA. Leptin and ovarian folliculogenesis: Implications for ovulation induction and ART outcomrs. Semin Reprod Med 2002;20(2):103-12.

13. Micic D, Macut $D$, Popovic V, et al. Leptin levels and insulin sensitivity in obese and non-obese patients with polycystic ovary syndrome. Gynecol Endocrinol 1997;11(5):315-20.

14. Chow TK, Phoon MC. Measurement of serum leptin concentrations in university undergraduates by competitive elisa reveals correlations wiyh body mass index and sex. Adv PhysiolEduc 2003;27(1-4):70-7.

15. Campfield LA, Smith FJ, Guisez Y, Devas R, Burn P. Recombinant Mouse OB protein: Evidence for a peripheral signal linking adiposity and central neural Networks. Science 1995;269(5223):546-9.

16. Mantzoros CS, Dunaif A, Flier JS. Leptin concentrations in the polycystic ovary syndrome. J Clin Endocrinol Metab 1997;82(6):1687-91.

17. Barash IA, Cheung CC, Weigle DS, et al. Leptin is a metabolic signal to the reproductive system. Endocrinology 1996;137(7):3144-7.

18. Rouru J, Anttila L, Koskinen P, et al. Serum leptin concentrations in women with polycystic ovarian syndrome. J Clin Endocrinol Metab 1997;82(6):1697-700.

19. Laughlin GA, Morales AJ, Yen SS. Serum leptin level in women with polycystic ovary syndrome: The role of insulin resistance/hyperinsulinemia. J Clin Endocrinol Metab 1997;82(6):1692-6.

20. Ferriman D, Gallwey JD. Clinical assessment of body hair growth in women. J Clinic Endocrinol 1961;21(11):1440-7.

21. Goodman N, Bledsoe M, Cobin R, et al. American Association of Clinical Endocrinologists medical guidelines for the clinical practice for the diagnosis and treatment of hyperandrogenic disorders. Endocr Pract 2001;7(2):120-34.

22. Hull MG, Savage PE, Bromham DR, Ismail AA, Morris AF. The value of a single serum progesterone measurement in the midluteal phase as a criterion of a potentially fertile cycle (ovulation) derived form treated and untreated conceptin cycles. Fertil Steril 1982;37(3):355-60.

23. Brzechffa PR, Jakimiuk AJ, Agarwal SK, Weitsman SR, Buyalos RP, Magoffln DA. Serum immunoreactive leptin concentrations in women wiyh polycystic ovary syndrome. Clin Endocrinol Metab 1996;81(11):4166-9.

24. Vicennati V, Gambineri A, Caizoni F, et al. Serum leptin in obese women with polycystic ovary syndrome is corelatedwith body weight and fat distribution but not with androgen and insulin levels. Metabolism 1998;47(8):988-92.

25. Lecke SB, Morsch DM, Spritzer PM. Association between adipose tissue expression and serum levels of leptin and adiponectin in women with polycystic ovary syndrome. Genetic and Molecular Research 2013;12(4):4292-4.

26. Moschos S, Chan JL. Leptin and reproduction: A review. Fertil Steril 2002;77(3):433-44.

27. Savastano S, Valentino R, Di Somma C, et al. Serum 25-Hydroxy vitamin D levels, phosphoprotein enriched in diabetes gene product (PED/PEA-15) and leptin-to-adiponectin ratio in women with PCOS. Nutr Metab 2011;23(8):84.

28. Lecke SB, Mattei F, Morsch DM, Spritzer PM. Abdominal subcutaneous fat gene expression and circulating levels of leptin and adiponectin in polycystic ovary syndrome. Fertil Steril 2011;95(6):2044-9.

29. Garutti G, de Paulo R, Rotelli MT, et al. Association between follicular fluid leptin and serum insulin levels in nonoverweight women with polycystic ovary syndrome. Biomed Res Int 2014;2014:980429.

30. Çimen S, Öztekin Ö, Gencer M, et al. Effects of female sex hormones and leptin levels on etiopathogenesis of polycystic ovary syndrome. Ege Tıp Dergisi; 2003;42(2):127-31.

31. Chapman IM, Wittert GA, Norman RJ. Circulating leptin concentrations in polycystic ovary syndrome: Relation to anthropometric and metabolic parameters. Clin Endocrinol 1997;46(2):175-81.

32. Spritzer PM, Poy M, Wiltgen D, Mylius LS, Capp E. Leptin concentrations in hirsute women with polycystic ovary syndrome or idiopathic hirsutism: Influence on LH and relationship with hormonal, metabolic, and anthropometric measurements. Hum Reprod 2001;16(7):1340-6.

33. Sahin I, Serter R, Karakurt F, et al. Leptin levels increase during flutamide therapy in women with polycystic ovary syndrome. Horm Res 2003;60(5):232-6.

34. Sağsöz N, Orbak Z, Noyan V, Yücel A, Uçar B, Yıldız L. The effcets of oral contaceptives including low-dose estrogen and drospirenone on the concentration of leptin and ghrelin in polycystic ovary syndrome. Fertil Steril 2009;92(2):660-6.

35. Imani B, Eijkemans $\mathrm{MJ}$, de Jong $\mathrm{FH}$, et al. Free androgen index and leptin are the most prominent endocrine predictors of ovarian response during clomiphene citrate induction of ovulation in normogonadotropic oligoamenorrheic infertility. J Clin Endocrinol Metab 2000;85(2):676-82. 